\title{
A simple, rapid, economical, and practical method for the determination of efavirenz in plasma of Chinese AIDS patients by reverse phase high-performance liquid chromatography with ultraviolet detector
}

\author{
Kang Yin ${ }^{1, *}$, Xianmin Meng ${ }^{2,3, *}$, Ping Dong ${ }^{2}$, Tianran Ding ${ }^{2}$, Li Shen ${ }^{2}$, Li Zhang ${ }^{2}$, Renfang Zhang ${ }^{1}$, \\ Weimin $\mathrm{Cai}^{3}$, Hongzhou $\mathrm{Lu}^{1, * *}$ \\ ${ }^{1}$ Department of Infectious Diseases, Shanghai Public Health Clinical Center, Shanghai, China; \\ ${ }^{2}$ Department of Pharmacy, Shanghai Public Health Clinical Center, Shanghai, China; \\ ${ }^{3}$ Department of Clinical Pharmacy and Pharmaceutical Administration, School of Pharmacy, Fudan University, Shanghai, China.
}

\begin{abstract}
Summary This study aimed to develop a reverse phase high-performance liquid chromatographic (RP-HPLC) method for the determination of efavirenz in human plasma and to use it for determining the concentrations of efavirenz in Chinese AIDS patient. A simple mobile phase consisting of $0.01 \mathrm{~mol} / \mathrm{L} \mathrm{NaH} \mathrm{PO}_{4}$ solution and acetonitrile $(38: 62, \mathrm{~V} / \mathrm{V})$ was pumped at a flow rate of $1.0 \mathrm{~mL} / \mathrm{min}$ through a reverse phase Diamonsil $\mathrm{C}_{18}$ column maintained at $30^{\circ} \mathrm{C}$. Diazepam was used as an internal standard and monitored with efavirenz at $247 \mathrm{~nm}$. The protein of $100 \mu \mathrm{L}$ plasma sample was precipitated before $20 \mu \mathrm{L}$ of the supernatant was directly injected into the column. The linear response over the concentration ranges $0.10-20.0$ $\mu \mathrm{g} / \mathrm{mL}$ was obtained and the linear regression equations was $\mathrm{Y}=\mathbf{2 . 2 8 7 3 X}-0.1449(r=0.9999)$. The intra-day and inter-day precisions $(1.9-2.6 \%, 2.2-7.2 \%$, respectively), the relative and absolute recovery $(\mathbf{9 9 . 3 - 1 0 6 . 3 \% , 7 5 . 6 - 8 0 . 3 \%}$, respectively) met the international standards. Stability of plasma samples were evaluated for short-term (ambient temperature for $16 \mathrm{~h}$ ) and long-term $\left(-20^{\circ} \mathrm{C}\right.$ for 30 days) storage conditions and were found to be stable. The mean plasma concentration of efavirenz of the 406 patients was $2.21 \pm 1.95 \mu \mathrm{g} / \mathrm{mL}, 77.3 \%$ of which were within the therapeutic window (1-4 $\mu \mathrm{g} / \mathrm{mL}), 15.1 \%$ were below the window, and $7.6 \%$ were over it. In conclusion, the method had advantages of convenience, rapidity, necessary accuracy and precision, high practicality and met the needs for therapeutic drug monitoring and the pharmacokinetic study of efavirenz, especially in underdeveloped countries. For Chinese AIDS patients, it was beneficial to use efavirenz under the guidance of therapeutic drug monitoring.
\end{abstract}

Keywords: Efavirenz, RP-HPLC, plasma concentration, AIDS

\section{Introduction}

Efavirenz, a non-nucleoside reverse transcriptase inhibitor for the treatment of HIV infection, is recommended by $\mathrm{WHO}$ as a first-line drug with its

\footnotetext{
*These authors contributed equally to this works.

**Address correspondence to:

Dr. Hongzhou Lu, Department of Infectious Diseases, Shanghai Public Health Clinical Center, 2901 Caolang Road,

Jinshan, Shanghai, 201508, China.

E-mail: luhongzhou@fudan.edu.cn
}

excellent therapeutic effect. It has been widely used over the world, especially in underdeveloped countries, such as China and some African countries (1). Efavirenz is mainly metabolized by CYP2B6 enzyme. However, cytochrome P450 2B6 gene exhibits highly degrees of polymorphism (2), which has a great difference in allele frequency among races, thus leading to obvious differences in efavirenz plasma concentration, either among individuals or among races (3-6). In addition, rifampicin and voriconazole, etc., which is often simultaneously used in HIV-infected patients for concurrent diseases, have interactions with efavirenz 
and affect efavirenz plasma concentration. Nowadays, many studies have shown that both the therapeutic effect and side effects of efavirenz are related to its plasma concentration $(3,4,7-11)$. The generally accepted therapeutic window of efavirenz is $1-4 \mu \mathrm{g} / \mathrm{mL}$ (steady state trough concentration). A long-time exposure to a lower efavirenz trough concentration may easily lead to virologic failure or virus resistance to efavirenz, while a higher trough concentration may result in a higher risk of side effects and toxicities $(7,11,12)$. A previous research shows that $28.6 \%$ of Chinese HIV-infected patients may have efavirenz plasma concentration above $4 \mu \mathrm{g} / \mathrm{mL}$ after taking a standard dose of efavirenz (600 mg, po, qd) (13). If we can monitor the plasma efavirenz concentration of the patients with efavirenz-containning antiretroviral treatment (ART) and adjust the dosage according to the results, a better therapeutic effect as well as a decline of side effects may be achieved (14-16), especially for patients taking rifampicin or voriconazole at the same time. Therefore, we need to develop a method for the quantitative determination of efavirenz in human plasma. Considering the actual situation in under-developed countries, the method must be simple, rapid, economical, and practical, with good accuracy and precision, selectivity, and sensitivity.

Up to now, several methods for the determination of efavirenz in plasma using LC-MS $(17,18)$, LC-MSMS (19,20), MALDI-TOF/IOF (21), HPLC-PAD (22$25)$, etc., have been published. These methods may not be widely used in underdeveloped countries because of the inaccessibility and high costs of laboratory equipments. On the contrary, reverse phase highperformance liquid chromatographic with ultraviolet detector (RP-HPLC-UV) method is feasible due to its easy accessibility and low cost. Also, many HPLC-UV methods for determination of plasma efavirenz $(23,26-$ 31 ) or simultaneous determination with other drugs such as anti-tuberculosis (anti-TB) agents or other antiretroviral agents $(24,32-50)$ have been reported. In most of these methods, the volumes of plasma used range from 200 to $900 \mu \mathrm{L}(23,26-28,33,34,44-46)$, which were inapplicable for children due to the scarcity of sample. High-cost, complicated and time-consuming plasma sample pre-treatments such as solid-phase extraction $(26,33,34,44-46)$, liquid-liquid extraction $(23,24,27,28,32,35)$ appeared in some methods. A few of reported methods were difficult to repeat because of the lack of internal standard (26). Moreover, some methods had complicated mobile phase $(34,37)$ or gradient elution $(35,40,50)$, and some had a longer system run time $(32,50)$. Therefore, none of the reported methods met all the requirements mentioned above. In our study we developed a method for plasma efavirenz determination by RP-HPLC with UV detector. In this method, $100 \mu \mathrm{L}$ sample plasma was precipitated by 200 $\mu \mathrm{L}$ acetonitrile (including internal standard: diazepam) and the supernatant was directly injected into HPLC system without dilution after mixing and centrifugation. Isocratic elution was applied and the detection time was $7.5 \mathrm{~min}$. The reliability and repeatability of this method was further verified by using it to determine efavirenz plasma concentrations in large samples. In a word, our method is simple, rapid, cost-effective, and can be applied in the therapeutic drug monitoring and pharmacokinetics researches on efavirenz, especially in underdeveloped countries.

\section{Materials and Methods}

\subsection{Chemicals}

Efavirenz standard (99.8\% purity) and efavirenz tablet (Stocrin $^{\circledR}$ ) were purchased from the Toronto Research Chemicals Inc. (North York, Canada, batch number 5-ABY-15-1) and Merck Sharp \& Dohme (South Granville, New South Wales, Australia), respectively. Diazepam (99.5\% purity, internal standard) was from the Sigma company (Shanghai, China, batch number 34H0556). Acetonitrile and methanol (HPLC grade) were obtained from Merck KGaA (Darmstadt, Germany), triethylamine and phosphoric acid (HPLC grade) from Tedia Company Inc (Fairfield, USA). $\mathrm{NaH}_{2} \mathrm{PO}_{4}$ was from Shanghai Clinical Research Center (Shanghai, China). Deionized water was processed through a water purification system (Yiyang Enterprise Development Company, Chongqing, China).

\subsection{Chromatographic system}

The HPLC system, Shimadzu LC-20A (Kyoto Japan), was consisted of column compartment CTO-20A, degasser DGU-20A5, pump CBM-20A, auto-sampler SIL-20AC, and SPD-20AV UV detector. The eluent was monitored at $247 \mathrm{~nm}$. Chromatographic separation was achieved at $30^{\circ} \mathrm{C}$ using a reverse phase YMCPack ODS-A C18 column $(\mathrm{C} 18,150 \mathrm{~mm} \times 4.6 \mathrm{~mm}, 5$ $\mu \mathrm{m})$ with a guard column (ZORBAX Eclipse Plus-C18, $150 \mathrm{~mm} \times 4.6 \mathrm{~mm}, 5 \mu \mathrm{m}$, Agilent Technologies, Santa Clara, USA). The mobile phase was consisted of 0.01 $\mathrm{mol} / \mathrm{L} \mathrm{NaH} \mathrm{PO}_{4}$ (containing $0.01 \mathrm{~mol} / \mathrm{L}$ triethylamine, $\mathrm{pH}$ 5.2) and acetonitrile (32:62, V/V), and pumped at a flow rate of $1.0 \mathrm{~mL} / \mathrm{min}$. The injection volume was 20 $\mu \mathrm{L}(26,28,31,32)$.

\subsection{Selection of study subjects, sample collection, and data collection}

Chinese AIDS outpatients, aging from 18 to 75 years, with no obvious hepatic or renal dysfunction, receiving efavirenz-containing ART at Shanghai Public Health Clinical Center from January 2012 to January 2013, were recruited to this study. Peripheral bloods (3-5 $\mathrm{mL}$ ) were drawn $16 \mathrm{~h}$ after the last dose, and were put into heparin anticoagulant tubes (51). Plasma samples 
were heat-inactivated $\left(56^{\circ} \mathrm{C}\right.$ water bath for $\left.60 \mathrm{~min}\right)$ and stored at $-80^{\circ} \mathrm{C}$ before they were analyzed. Correlated information of the patients was collected, including gender, age, weight, height, hepatic and renal functions, antiretroviral regimen, efavirenz dosage, time of taking medicine, time of blood sample collection, drug combinations and adverse drug reactions (ADR). The study followed the Declaration of Helsinki and ethics approval was granted by the Ethics Committee of Shanghai Public Health Clinical Center. Written informed consent was obtained from each patient.

\subsection{Preparation of various solutions}

$\mathrm{NaH}_{2} \mathrm{PO}_{4}$ buffer solution was prepared by dissolving accurately weighed $\mathrm{NaH}_{2} \mathrm{PO}_{4}$ (3.1202 g) and triethylamine $(2.0238 \mathrm{~g})$ in $2 \mathrm{~L}$ ultrapure water and blended well by ultrasonic. The $\mathrm{pH}$ value was adjusted to 5.2 using $20 \%$ phosphoric acid. The solution was degassed by ultrasonic for $20 \mathrm{~min}$ after vacuum filtration before using. Two hundred $\mu \mathrm{g} / \mathrm{mL}$ efavirenz stock solution was prepared by dissolving accurately weighed efavirenz standard $(10 \mathrm{mg})$ into a $50 \mathrm{~mL}$ mixture of methanol and water $(1: 1, \mathrm{~V} / \mathrm{V})$, and stored at $4{ }^{\circ} \mathrm{C}$ before using. Working solutions of efavirenz in concentrations of $1,2,5,10,20,30,40,80,100$, and $160 \mu \mathrm{g} / \mathrm{mL}$ were prepared by diluting stock solution of efavirenz with the mixture of methanol and water (1:1, $\mathrm{V} / \mathrm{V})$. The diazepam stock solution $(100 \mu \mathrm{g} / \mathrm{mL})$ was prepared by dissolving accurately weighed diazepam $(10 \mathrm{mg})$ in $100 \mathrm{~mL}$ acetonitrile and stored at $4^{\circ} \mathrm{C}$. Before sample preparation, $1 \mu \mathrm{g} / \mathrm{mL}$ diazepam working solution was prepared by diluting stock solution with acetonitrile.

\subsection{Sample preparation}

One hundred $\mu \mathrm{L}$ plasma sample was transferred to 2 $\mathrm{mL}$ centrifuge tubes and $200 \mu \mathrm{L}$ of diazepam working solution (acetonitrile with $1 \mu \mathrm{g} / \mathrm{mL}$ diazepam) was added. The mixture was blended for $2 \mathrm{~min}$ and was laid aside for $10 \mathrm{~min}$ at room temperature, then centrifuged at $15,000 \mathrm{rpm} / \mathrm{min}$ for $6 \mathrm{~min}$. Twenty $\mu \mathrm{L}$ of the supernatant was directly injected into HPLC system under the condition described in 2.2. The chromatograms were recorded and concentrations of efavirenz were calculated.

\subsection{Statistical methods}

Descriptive analysis was performed to determine the mean and the standard deviation (mean \pm S.D.) for continuous variables such as age, height, body mass index (BMI), and the percentages for categorical variables such as sex. Plasma efavirenz concentrations were showed as mean \pm S.D. Statistical analysis was carried out by SPSS 18.0. Normality test of the plasma efavirenz concentrations of different groups was assessed by Kolmogorov-Smirnov method before comparing. Levene's test was applied to determine variance homogeneity. Plasma efavirenz concentrations of multiple groups were compared with single factor analysis of variance. The comparison between two groups was performed with $t$-test if the data comply with the normal distribution. If not, difference tests were done using Mann-Whitney test or Kruskal-Wallis test. Analyses were done two-sided, and the result was considered as significance when the $\mathrm{p}$ value was below 0.05 .

\section{Results}

\subsection{Chromatographic behavior}

Figure 1 showed the typical Chromatograms of blank plasma (C), blank plasma spiked with efavirenz and diazepam (B), and plasma sample from a patient following the oral administration of $600 \mathrm{mg}$ efavirenz tablet above two weeks (A). The retention times of efavirenz and diazepam were $6.475 \mathrm{~min}$ and $4.535 \mathrm{~min}$, respectively. The peaks of the two components were well separated, whilst no endogenous compounds peak was found beside the peaks of efavirenz and diazepam in blank plasma. The retention times of efavirenz and diazepam from patient's plasma sample are the same as those from standard substances, with good peak shapes and no interference peaks.

\subsection{Drug combination test}

In clinical practice, efavirenz is often used simultaneously with other drugs such as fluconazole, voriconazole, zidovudine, lamivudine, stavudine, tenofovir, ritonavir, and rifampin, etc. In order to evaluate the effect of these drugs on chromatographic peaks of efavirenz and diazepam, $2 \mu \mathrm{g} / \mathrm{mL}$ standard solutions of above drug were prepared and $20 \mu \mathrm{L}$ was injected into the HPLC system, respectively. The chromatograms showed that

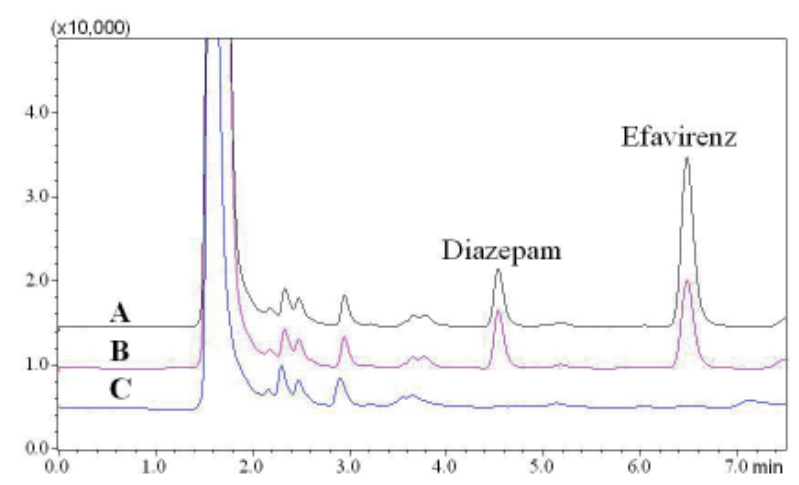

Figure 1. Chromatograms of efavirenz (retention time $6.475 \mathrm{~min}$ ) and diazepam (retention time $\mathbf{4 . 5 3 5}$ min) from extracted plasma sample from patient $(A)$; Chromatograms of spiked plasma sample containing efavirenz and diazepam standard (B); Chromatogram of extracted blank plasma (C). 
the drugs above had no interference on the peak of efavirenz and diazepam.

\subsection{Linearity}

Different concentrations of efavirenz $(0.10,0.50,1.0,2.0$, $4.0,8.0,16 \mu \mathrm{g} / \mathrm{mL})$ were prepared using blank plasma and standard substance. $0.1 \mathrm{~mL}$ sample plasma of each concentration was processed according to the sample preparation method and was quantified. According to the chromatography, the concentration of efavirenz (Y) between 0.10 and $16.0 \mu \mathrm{g} / \mathrm{mL}$ had a good linear correlation with the ratio of peak areas of efavirenz and diazepam, and a regression equation was established: $\mathrm{Y}$ $=2.2873 \mathrm{X}-0.1449(r=0.9999)$. The lowest detection limit was $0.027 \mu \mathrm{g} / \mathrm{mL}(\mathrm{S} / \mathrm{N}=3)$, while limit of quantification was $0.089 \mu \mathrm{g} / \mathrm{mL}(\mathrm{S} / \mathrm{N}=10)$.

\subsection{Recovery}

Varying concentrations of efavirenz quality control samples $(0.3,3.0$, and $10.0 \mu \mathrm{g} / \mathrm{mL})$ were prepared in blank human plasma and extracted as described above. Relative recovery was calculated by comparing the measured concentration according to regression equation with added concentration. Absolute recovery of the efavirenz was determined by comparing the peak area ratio after extraction with those of un-extracted solutions containing same concentrations of efavirenz as in plasma (Table 1). The relative recovery was $99.3-106.3 \%$ with RSD ranging from $3.2 \%$ to $4.5 \%$, and the absolute recovery was $75.6-80.3 \%$ with RSD ranged from $2.8 \%$ to $4.8 \%$.

\subsection{Accuracy and precision}

In order to evaluate the accuracy and precision of the method, three different concentrations quality control samples of efavirenz $(0.2,3.0,10.0 \mu \mathrm{g} / \mathrm{mL})$ were prepared in blank human plasma and extracted as described above. Intra-day assay accuracy and precision was determined from the analysis of five replicate samples at each of the low, mid and high quality control standards, whereas, inter-day accuracy and precision involved the calculation of the mean values of fifteen samples at each of the low, mid and high quality control standards over three different days (Table 2). The intraday and inter-day precision was $1.9-2.6 \%$ and $2.2-7.2 \%$, respectively.

\subsection{Stability}

\subsubsection{Stability of stock solution}

Stock solution of efavirenz $(200 \mu \mathrm{g} / \mathrm{mL})$ was taken out at day $1,15,30,45$, and 60 , and then dissolved in methanolwater $(1: 1, \mathrm{~V} / \mathrm{V})$ at a concentration of $2 \mu \mathrm{g} / \mathrm{mL}$, while stock solution of diazepam was dissolved in acetonitrile at a concentration of $1 \mu \mathrm{g} / \mathrm{mL}, 20 \mu \mathrm{L}$ of each of which was injected into the HPLC system and determined under the chromatographic condition described in 2.2. The RSD of efavirenz and diazepam was $1.3 \%$ and $1.4 \%$, proving the stability of stock solution of efavirenz and that of diazepam within 60 days.

\subsubsection{Stability of plasma samples at ambient temperature}

Three different concentrations samples of efavirenz (0.2, $3.0,10.0 \mu \mathrm{g} / \mathrm{mL}$ ) were prepared in blank human plasma and were laid aside at room temperature. Samples of each concentration were extracted at $0,2,4,8,16 \mathrm{~h}$ and quantified by the HPLC system. The RSD of efavirenz at concentrations of $0.2,3.0$ and $10.0 \mu \mathrm{g} / \mathrm{mL}$ were $6.0 \%$, $3.1 \%$ and $2.5 \%$, respectively, proving the stability of plasma samples at ambient temperature in at least $16 \mathrm{~h}$.

\subsubsection{Stability at freezing state}

Three different concentrations samples of efavirenz (0.2, $3.0,10.0 \mu \mathrm{g} / \mathrm{mL}$ ) were prepared in blank human plasma and stored at $-20^{\circ} \mathrm{C}$. The frozen samples were taken out at day $0,3,6,15$, and 30 , and processed. The efavirenz concentrations of these samples were determined. The RSD of efavirenz at concentrations of $0.2,3.0$, and

Table 1. Results of recovery test of efavirenz

\begin{tabular}{|c|c|c|c|c|c|c|}
\hline \multirow{2}{*}{ Expected $(\mu \mathrm{g} / \mathrm{mL})$} & \multicolumn{3}{|c|}{ Relative recovery } & \multicolumn{3}{|c|}{ Absolute recovery } \\
\hline & Mean \pm S.D., $n=5$ & Recovery & RSD & Mean \pm S.D., $n=5$ & Recovery & RSD \\
\hline 0.30 & $0.319 \pm 0.014$ & $106.3 \%$ & $4.5 \%$ & $0.756 \pm 0.021$ & $75.6 \%$ & $2.8 \%$ \\
\hline 3.00 & $2.978 \pm 0.095$ & $99.3 \%$ & $3.2 \%$ & $0.777 \pm 0.033$ & $77.7 \%$ & $4.2 \%$ \\
\hline 10.00 & $10.316 \pm 0.384$ & $103.2 \%$ & $3.7 \%$ & $0.803 \pm 0.038$ & $80.3 \%$ & $4.8 \%$ \\
\hline
\end{tabular}

Table 2. Results of intra-day and inter-day accuracy and precision test of efavirenz

\begin{tabular}{|c|c|c|c|c|c|c|}
\hline \multirow{2}{*}{ Expected $(\mu \mathrm{g} / \mathrm{mL})$} & \multicolumn{3}{|c|}{ Intra-day $(n=5)$} & \multicolumn{3}{|c|}{ Inter-day $(n=15)$} \\
\hline & Mean \pm S.D., $\mu \mathrm{g} / \mathrm{mL}$ & Accuracy & Precision & Mean \pm S.D., $\mu \mathrm{g} / \mathrm{mL}$ & Accuracy & Precision \\
\hline 0.30 & $0.311 \pm 0.006$ & $3.7 \%$ & $1.9 \%$ & $0.318 \pm 0.023$ & $6.0 \%$ & $7.2 \%$ \\
\hline 3.00 & $3.070 \pm 0.075$ & $2.3 \%$ & $2.4 \%$ & $3.009 \pm 0.066$ & $0.3 \%$ & $2.2 \%$ \\
\hline 10.00 & $10.473 \pm 0.267$ & $4.7 \%$ & $2.6 \%$ & $10.337 \pm 0.229$ & $3.4 \%$ & $2.2 \%$ \\
\hline
\end{tabular}


Table 3. Demographic data and ART regimens, and influence on the efavirenz plasma concentrations

\begin{tabular}{|c|c|c|c|c|c|}
\hline Factors & Categories & $n$ & Percentage (\%) & Mean \pm S.D. $(\mu \mathrm{g} / \mathrm{mL})$ & $p$ \\
\hline \multirow[t]{2}{*}{ Gender } & Male & 364 & 89.7 & $2.18 \pm 1.89$ & \multirow[t]{2}{*}{0.646} \\
\hline & Female & 42 & 10.3 & $2.46 \pm 2.40$ & \\
\hline \multirow[t]{2}{*}{ Age } & $<60$ & 374 & 92.1 & $2.20 \pm 1.96$ & \multirow[t]{2}{*}{0.641} \\
\hline & $\geq 60$ & 32 & 7.9 & $2.31 \pm 1.89$ & \\
\hline \multirow[t]{2}{*}{ BMI } & $<25$ & 105 & 25.7 & $2.23 \pm 2.32$ & \multirow[t]{2}{*}{0.529} \\
\hline & $\geq 25$ & 301 & 74.1 & $2.20 \pm 1.80$ & \\
\hline \multirow[t]{4}{*}{ ART regimens } & Zidovudine + Lamivudine + Efavirenz & 224 & 55.2 & $2.24 \pm 2.05$ & \multirow[t]{4}{*}{0.206} \\
\hline & Stavudine + Lamivudine + Efavirenz & 109 & 26.8 & $2.27 \pm 2.07$ & \\
\hline & Tenofovir + Lamivudine + Efavirenz & 65 & 16.0 & $1.95 \pm 1.39$ & \\
\hline & Others & 8 & 2.0 & $2.53 \pm 1.16$ & \\
\hline
\end{tabular}

$10.0 \mu \mathrm{g} / \mathrm{mL}$ were $4.3 \%, 5.2 \%$, and $3.6 \%$, respectively, proving the stability of plasma samples at $-20^{\circ} \mathrm{C}$ in at least 30 days.

\subsubsection{Stability of freezing and thawing cycles}

Three different concentrations samples of efavirenz $(0.2,3.0,10.0 \mu \mathrm{g} / \mathrm{mL})$ were prepared in blank human plasma and extracted after three times freezing and thawing cycles. The RSD of efavirenz at concentrations of $0.3,3.0$, and $10.0 \mu \mathrm{g} / \mathrm{mL}$ were $7.7 \%, 4.1 \%$, and $1.3 \%$, respectively, proving the stability of plasma samples after exposing to three freeze-thaw cycles.

\subsubsection{Stability of re-dissolved supernatants at ambient temperature}

Efavirenz with blank plasma at concentrations of 0.2, 3.0, and $10.0 \mu \mathrm{g} / \mathrm{mL}$ were dealt with according to the method described above. The supernatants were assessed for stability at ambient temperature at hour $0,3,6$, and 12 . The RSD of efavirenz concentration were 5.2\%, 4.3\%, and $2.0 \%$, respectively, which proved the stability of redissolved supernatants in $12 \mathrm{~h}$ at ambient temperature.

\subsection{Clinical application}

Four hundred and six plasma samples of Chinese AIDS patients were dealt with and determined. The mean steady state trough concentration of the 406 patients was $2.21 \pm 1.95 \mu \mathrm{g} / \mathrm{mL}, 77.3 \%$ of which were within the therapeutic window (1-4 $\mu \mathrm{g} / \mathrm{mL}), 15.1 \%$ were below the window, and $7.6 \%$ were over it. The highest concentration was $14.89 \mu \mathrm{g} / \mathrm{mL}, 36$ folds as the lowest concentration $(0.41 \mu \mathrm{g} / \mathrm{mL})$. Plasma efavirenz concentrations had no significant difference among the groups $(p>0.05)$ divided by the patients' gender, age, BMI and therapeutic regimen (Table 3).

\section{Discussion}

As mentioned above, although there are many methods for determination of efavirenz in plasma, most of them have high requirements for equipments and technologies, hardly repeated in undeveloped countries. The method established in this paper, by RP-HPLC with UV detector, has a lower requirement for equipments compared to reported methods (17-25). In our method, diazepam was used as internal standard because of its cheapness, accessibility, and well-separated with efavirenz. But patients who take diazepam had to be excluded so as to avoid the interference on the results. For sample pretreatment, $100 \mu \mathrm{L}$ plasma was mixed with $200 \mu \mathrm{L}$ acetonitrile (with $1 \mu \mathrm{g} / \mathrm{mL}$ diazepam) to precipitate protein, and the mixture was centrifuged and then the supernatant was directly injected into the HPLC system. In contrast to solid-phase extraction, liquid-liquid extraction $(23,24,26-28,32-35,38,44-$ 46), this method has advantages of simplicity, rapidity, economical and low requirement for plasma volume, suitable for pediatric patients. As shown in Figure 1, endogenous substances have no interference on the peak of efavirenz and diazepam, and the column pressure have no obvious rise after the determination of over 400 plasma samples, which indicated that plasma proteins could be precipitated completely in this method. The detection wavelength of 245, 246, 247, $250 \mathrm{~nm}$ were used in different methods $(26,28,31,33)$. In our study, $100 \mu \mathrm{g} / \mathrm{mL}$ solution of efavirenz standard were scanned by ultraviolet spectrophotometer ranging from 190-500 $\mathrm{nm}$, and a maximum absorption was achieved at $247 \mathrm{~nm}$ with no interference, so $247 \mathrm{~nm}$ was chosen as detective wavelength.

As to mobile phase, complicated mobile phase and time-wasting gradient elution were reported. In this paper, we finally took $0.01 \mathrm{~mol} / \mathrm{L} \mathrm{NaH}_{2} \mathrm{PO}_{4}$ (containing $0.01 \mathrm{~mol} / \mathrm{L}$ triethylamine, $\mathrm{pH}$ 5.2)-acetonitrile $(38: 62, \mathrm{~V} /$ $\mathrm{V})$ as mobile phase after repeated attempts with reference to other reports $(26,28,31,32)$. The addition of diluted phosphoric acid and triethylamine adjusted the $\mathrm{pH}$ of the mobile phase, improved the peak shapes of the efavirenz and diazepam. Under the chromatographic conditions described above, the system run time was $7.5 \mathrm{~min}$ and efavirenz was well-separated from internal standard 
diazepam with good peak shapes. The retention times of efavirenz and diazepam were $6.475 \mathrm{~min}$ and 4.535 min, respectively. Figure 1 showed that blank plasma samples had no peak near the retention time of efavirenz and diazepam. No endogenous substances or other coadministered drugs such as zidovudine, lamivudine, stavudine, tenofovir, ritonavir, lopinavir, fluconazole, voriconazole, and rifampicin interfered with the chromatogram of efavirenz and diazepam. The standard curve parameters of efavirenz concentrations ranging from 0.10 to $16.0 \mu \mathrm{g} / \mathrm{mL}$ showed a linear relationship between peak area and concentrations. The absolute recoveries of efavirenz at a concentration of $0.3,3.0$, and 10.0 were $75.6 \%, 77.7 \%$, and $80.3 \%$, while the relative recovery were $106 \%, 99.3 \%$, and $103 \%$, respectively. The intra-day and inter-day RSD for standards at a concentration of $0.3,3.0$, and $10.0 \mu \mathrm{g} / \mathrm{mL}$ ranged from 1.9 to $2.6 \%$ and 2.2 to $7.2 \%$. The lowest detection limit and limit of quantification estimated mathematically from the standard curve equation were $27 \mathrm{ng} / \mathrm{mL}$ and $89 \mathrm{ng} / \mathrm{mL}$, respectively. Via the tests on the repetitiveness, accuracy and the stability, supposed this method was reliable.

The mean efavirenz concentration of 406 Chinese AIDS patients was $2.21 \pm 1.95 \mu \mathrm{g} / \mathrm{mL}$, which was in accordance with two other published papers related to Chinese patients $(13,52)$, but a little lower than that of Spanish $(2.27 \mu \mathrm{g} / \mathrm{mL})(53)$. Of all the plasma samples, $77.3 \%$ were within the therapeutic window of $1-4 \mu \mathrm{g} / \mathrm{mL}, 15.1 \%$ below $1 \mu \mathrm{g} / \mathrm{mL}$, and $7.6 \%$ over $4 \mu \mathrm{g} / \mathrm{mL}$, which showed that a considerable proportion of Chinese patients might have a higher risk of treatment failure or ADR. There was no significant difference of plasma efavirenz concentrations among the groups divided according to gender, age, BMI, and ART regimens, which indicated that efavirenz concentrations would not be influenced by demographic backgrounds or regimens in Chinese patients. It had been reported that the main reason leading to wide intraand inter-individual variability of plasma efavirenz concentrations was the polymorphism of $C Y P 2 B 6$ gene. For example, CYP2B6 $516 \mathrm{G}>\mathrm{T}$, a SNP highly related to the concentration of efavirenz, has a high mutation frequency. In Chinese, the mutation frequency of the SNP was at a higher level, 18-35\% from different reports (52,54-56). This may well explain part of the difference in plasma efavirenz concentrations in Chinese AIDS patients. Therefore, in virtue of the great difference in pharmacodynamics and pharmacokinetics of efavirenz among races and individuals, the close relationship between therapeutic effects or side effects and its plasma concentration, and the higher prices of efavirenz, the dose of efavirenz should be individualized on the basis of therapeutic drug monitoring for patients with high frequency of $C Y P 2 B 6$, so as to improve therapeutic efficacy, to reduce the incidence of ADR, and to cut public health expenditure.

In conclusion, with its simplicity, fastness, accuracy and reliability, the method introduced above is suitable for therapeutic drug monitoring and pharmacokinetic study of efavirenz, especially in economically challenged countries. Chinese AIDS patients, with the great interindividual difference of plasma efavirenz concentrations, need therapeutic drug monitoring when taking efavirenz.

\section{Acknowledgements}

This work was supported by the 12th Five-year Plan, the People's Republic of China (NO: 2012ZX10001003); the 12th Five-Year Major New Drug Discovery Science and Technology: Technology Platform Construction of antiHIV drugs clinical evaluation (NO: 2012ZX09303013), the People's Republic of China; and Shanghai municipal natural science foundation (14ZR1434900). We thank all the patients and research assistants for their cooperation.

\section{References}

1. Bock P, Fatti G, Grimwood A. Comparing the effectiveness of efavirenz and nevirapine for first-line antiretroviral therapy in a South African multicentre cohort. Int Health. 2013; 5:132-138.

2. Ward BA, Gorski JC, Jones DR, Hall SD, Flockhart DA, Desta Z.Gorski JC, Jones DR. The cytochrome P4502B6 (CYP2B6) is the main catalyst of efavirenz primary and secondary metabolism: Implication for HIV/AIDS therapy and utility of efavirenz as a substrate marker of CYP2B6 catalytic activity. J Pharmacol Exp Ther. 2003; 306:287300 .

3. Stahle L, Moberg L, Svensson JO, Sonnerborg A. Efavirenz plasma concentrations in HIV-infected patients - Inter- and intraindividual variability and clinical effects. Ther Drug Monit. 2004; 26:267-270.

4. Aurpibul L, Chotirosniramit N, Sugandhavesa P, Kosashunhanan N, Thetket S, Supindham T, Piyamongkol W, Supparatpinyo K. Correlation of CYP2B6-516 G>T Polymorphism with Plasma Efavirenz Concentration and Depression in HIV-Infected Adults in Northern Thailand. Curr HIV Res. 2012; 10:653-660.

5. Desta Z, Saussele T, Ward B, Blievernicht J, Li L, Klein K, Flockhart D, Zanger UM. Impact of CYP2B6 polymorphism on hepatic efavirenz metabolism in vitro. Pharmacogenomics. 2007; 8:547-558.

6. Nyakutira C, Roshammar D, Chigutsa E, Chonzi P, Ashton M, Nhachi C, Masimirembwa C. High prevalence of the CYP2B6 516G $\rightarrow \mathrm{T}\left({ }^{*} 6\right)$ variant and effect on the population pharmacokinetics of efavirenz in HIV/AIDS outpatients in Zimbabwe. Eur J Clin Pharmacol. 2008; 64:357-365.

7. Marzolini C, Telenti A, Decosterd LA, Greub G, Biollaz J, Buclin T. Efavirenz plasma levels can predict treatment failure and central nervous system side effects in HIV-1infected patients. Aids. 2001; 15:71-75.

8. Gutierrez F, Navarro A, Padilla S, Anton R, Masia M, Borras J, Martin-Hidalgo A. Prediction of neuropsychiatric adverse events associated with long-term efavirenz therapy, using plasma drug level monitoring. Clin Infect Dis. 2005; 41:1648-1653.

9. Yimer G, Amogne W, Habtewold A, Makonnen E, Ueda N, Suda A, Worku A, Haefeli WE, Burhenne J, Aderaye 
G, Lindquist L, Aklillu E. High plasma efavirenz level and $C Y P 2 B 6(*) 6$ are associated with efavirenz-based HAART-induced liver injury in the treatment of naive HIV patients from Ethiopia: a prospective cohort study. Pharmacogenomics J. 2012; 12:499-506.

10. Langmann P, Weissbrich B, Desch S, Vath T, Schirmer D, Zilly M, Klinker H. Efavirenz plasma levels for the prediction of treatment failure in heavily pretreated HIV-1 infected patients. Eur J Med Res. 2002; 7:309-314.

11. Kappelhoff BS, van Leth F, Robinson PA, MacGregor TR, Baraldi E, Montella F, Uip DE, Thompson MA, Russell DB, Lange JMA, Beijnen JH, Huitema ADR, 2NN Study Group. Are adverse events of nevirapine and efavirenz related to plasma concentrations? Antivir Ther (Lond). 2005; 10:489-498.

12. Mukonzo JK, Okwera A, Nakasujja N, Luzze H, Sebuwufu D, Ogwal-Okeng J, Waako P, Gustafsson LL, Aklillu E. Influence of efavirenz pharmacokinetics and pharmacogenetics on neuropsychological disorders in Ugandan HIV-positive patients with or without tuberculosis: a prospective cohort study. BMC Infect Dis. 2013; 13:261.

13. Sun J, Chen J, Yao Y, Zhang R, Zheng Y, Liu L, Zhang L, Shen Y, Lu H. Minimum effective plasma concentration of efavirenz in treatment-naive Chinese HIV-infected patients. Int J STD AIDS. 2010; 21:810-813.

14. Johnson DH, Gebretsadik T, Shintani A, Mayo G, Acosta EP, Stein CM, Haas DW. Neuropsychometric correlates of efavirenz pharmacokinetics and pharmacogenetics following a single oral dose. Br J Clin Pharmacol. 2013; 75:997-1006.

15. Solas C, Gagnieu MC. Evidence-based therapeutic drug monitoring for efavirenz. Therapie. 2011; 66:197-205.

16. Rotger M, Telenti A. Optimizing efavirenz treatment: CYP2B6 genotyping or therapeutic drug monitoring? Eur J Clin Pharmacol. 2008; 64:335-336.

17. Rouzes A, Berthoin K, Xuereb F, Djabarouti S, Pellegrin I, Pellegrin JL, Coupet AC, Augagneur S, Budzinski H, Saux MC, Breilh D. Simultaneous determination of the antiretroviral agents: amprenavir, lopinavir, ritonavir, saquinavir and efavirenz in human peripheral blood mononuclear cells by high-performance liquid chromatography-mass spectrometry. J Chromatogr B Analyt Technol Biomed Life Sci. 2004; 813:209-216.

18. Martin J, Deslandes G, Dailly E, Renaud C, Reliquet V, Raffi F, Jolliet P. A liquid chromatographytandem mass spectrometry assay for quantification of nevirapine, indinavir, atazanavir, amprenavir, saquinavir, ritonavir, lopinavir, efavirenz, tipranavir, darunavir and maraviroc in the plasma of patients infected with HIV. J Chromatogr B Analyt Technol Biomed Life Sci. 2009; 877:3072-3082.

19. Avery LB, Parsons TL, Meyers DJ, Hubbard WC. A highly sensitive ultra performance liquid chromatographytandem mass spectrometric (UPLC-MS/MS) technique for quantitation of protein free and bound efavirenz (EFV) in human seminal and blood plasma. J Chromatogr B Analyt Technol Biomed Life Sci. 2010; 878:3217-3224.

20. Kim KB, Kim H, Jiang F, Yeo C-W, Bae SK, Desta Z, Shin JG, Liu KH. Rapid and simultaneous determination of efavirenz, 8-hydroxyefavirenz, and 8,14-dihydroxyefavirenz using LC-MS-MS in human plasma and application to pharmacokinetics in healthy volunteers. Chromatographia. 2011; 73:263-271.

21. Notari S, Mancone C, Alonzi T, Tripodi M, Narciso
P, Ascenzi P. Determination of abacavir, amprenavir, didanosine, efavirenz, nevirapine, and stavudine concentration in human plasma by MALDI-TOF/TOF. J Chromatogr B Analyt Technol Biomed Life Sci. 2008; 863:249-257.

22. Matthews CZ, Woolf EJ, Mazenko RS, HaddixWiener H, Chavez-Eng CM, Constanzer ML, Doss GA, Matuszewski BK. Determination of efavirenz, a selective non-nucleoside reverse transcriptase inhibitor, in human plasma using HPLC with post-column photochemical derivatization and fluorescence detection. J Pharm Biomed Anal. 2002; 28:925-934.

23. Langmann P, Schirmer D, Väth T, Zilly M, Klinker H. High-performance liquid chromatographic method for the determination of HIV-1 non-nucleoside reverse transcriptase inhibitor efavirenz in plasma of patients during highly active antiretroviral therapy. J Chromatogr B Biomed Sci Appl. 2001; 755:151-156.

24. Poirier J-M, Robidou P, Jaillon P. Simple and simultaneous determination of the hiv-protease inhibitors amprenavir, atazanavir, indinavir, lopinavir, nelfinavir, ritonavir and saquinavir plus M8 nelfinavir metabolite and the nonnucleoside reverse transcriptase inhibitors efavirenz and nevirapine in human plasma by reversed-phase liquid chromatography. Ther Drug Monit. 2005; 27:186-192.

25. Dogan-Topal B, Ozkan SA, Uslu B. Simultaneous determination of abacavir, efavirenz and valganciclovir in human serum samples by isocratic HPLC-DAD detection. Chromatographia. 2007; 66:S25-S30.

26. Saras-Nacenta M, López-Púa Y, Lípez-Cortés LF, Mallolas J, Gatell JM, Carné X. Determination of efavirenz in human plasma by high-performance liquid chromatography with ultraviolet detection. J Chromatogr B Biomed Sci Appl. 2001; 763:53-59.

27. Sailaja AL, Kumar KK, Kumar DVRR, Kumar CM, Yugandhar NM, Srinubabu G. Development and validation of a liquid chromatographic method for determination of efavirenz in human plasma. Chromatographia. 2007; 65:359-361.

28. Ramachandran G, Kumar AKH, Swaminathan S, Venkatesan P, Kumaraswami V, Greenblatt DJ. Simple and rapid liquid chromatography method for determination of efavirenz in plasma. J Chromatogr B Analyt Technol Biomed Life Sci. 2006; 835:131-135.

29. Veldkamp AI, van Heeswijk RP, Meenhorst PL, Mulder JW, Lange JM, Beijnen JH, Hoetelmans RM. Quantitative determination of efavirenz (DMP 266), a novel nonnucleoside reverse transcriptase inhibitor, in human plasma using isocratic reversed-phase high-performance liquid chromatography with ultraviolet detection. J Chromatogr B Biomed Sci Appl. 1999; 734:55-61.

30. Villani P, Pregnolato M, Banfo S, Rettani M, Burroni D, Seminari E, Maserati R, Regazzi MB. High-performance liquid chromatography method for analyzing the antiretroviral agent efavirenz in human plasma. Ther Drug Monit. 1999; 21:346-350.

31. Mogatle S, Kanfer I. Rapid method for the quantitative determination of efavirenz in human plasma. J Pharm Biomed Anal. 2009; 49:1308-1312.

32. Takahashi M, Yoshida M, Oki T, Okumura N, Suzuki T, Kaneda T. Conventional HPLC method used for simultaneous determination of the seven HIV protease inhibitors and nonnucleoside reverse transcription inhibitor efavirenz in human plasma. Biol Pharm Bull. 2005; 28:1286-1290. 
33. Fox D, O'Connor R, Mallon P, McMahon G. Simultaneous determination of efavirenz, rifampicin and its metabolite desacetyl rifampicin levels in human plasma. J Pharm Biomed Anal. 2011; 56:785-791.

34. Aymard G, Legrand M, Trichereau N, Diquet B. Determination of twelve antiretroviral agents in human plasma sample using reversed-phase high-performance liquid chromatography. J Chromatogr B Biomed Sci Appl. 2000; 744:227-240.

35. Titier K, Lagrange E, Pehourcq F, Edno-Mcheik L, Moore N, Molimard M. Simultaneous assay of antiretroviral drugs in human plasma by high performance liquid chromatography. Therapie. 2002; 57:169-174.

36. Boffito M, Tija J, Reynolds HE, Hoggard PG, Bonora S, Di Perri G, Back DJ. Simultaneous determination of rifampicin and efavirenz in plasma. Ther Drug Monit. 2002; 24:670-674.

37. Cociglio M, Hillaire-Buys D, Peyrière H, Alric R. Performance analysis of a rapid HPLC determination with the solvent demixing extraction of HIV antiproteases and efavirenz in plasma. J Chromatogr Sci. 2003; 41:80-86.

38. Kappelhoff BS, Rosing H, Huitema ADR, Beijnen JH. Simple and rapid method for the simultaneous determination of the non-nucleoside reverse transcriptase inhibitors efavirenz and nevirapine in human plasma using liquid chromatography. J Chromatogr B Analyt Technol Biomed Life Sci. 2003; 792:353-362.

39. Keil K, Frerichs VA, DiFrancesco R, Morse G. Reverse phase high-performance liquid chromatography method for the analysis of amprenavir, efavirenz, indinavir, lopinavir, nelfinavir and its active metabolite (M8), ritonavir, and saquinavir in heparinized human plasma. Ther Drug Monit. 2003; 25:340-346.

40. Dailly E, Raffi F, Jolliet P. Determination of atazanavir and other antiretroviral drugs (indinavir, amprenavir, nelfinavir and its active metabolite M8, saquinavir, ritonavir, lopinavir, nevirapine and efavirenz) plasma levels by high performance liquid chromatography with UV detection. J Chromatogr B Analyt Technol Biomed Life Sci. 2004; 813:353-358.

41. Choi SO, Rezk NL, Kashuba ADM. High-performance liquid chromatography assay for the determination of the HIV-protease inhibitor tipranavir in human plasma in combination with nine other antiretroviral medications. J Pharm Biomed Anal. 2007; 43:1562-1567.

42. Marzolini C, Telenti A, Buclin T, Biollaz J, Decosterd LA. Simultaneous determination of the HIV protease inhibitors indinavir, amprenavir, saquinavir, ritonavir, nelfinavir and the non-nucleoside reverse transcriptase inhibitor efavirenz by high-performance liquid chromatography after solid-phase extraction. J Chromatogr B Biomed Sci Appl. 2000; 740:43-58.

43. Notari S, Bocedi A, Ippolito G, Narciso P, Pucillo LP, Tossini G, Donnorso RP, Gasparrini F, Ascenzi P. Simultaneous determination of 16 anti-HIV drugs in human plasma by high-performance liquid chromatography. J Chromatogr B Analyt Technol Biomed Life Sci. 2006; 831:258-266.

44. Rezk NL, Tidwell RR, Kashuba ADM. High-performance liquid chromatography assay for the quantification of HIV protease inhibitors and non-nucleoside reverse transcriptase inhibitors in human plasma. J Chromatogr B
Analyt Technol Biomed Life Sci. 2004; 805:241-247.

45. Simon VA, Thiam MD, Lipford LC. Determination of serum levels of thirteen human immunodeficiency virus-suppressing drugs by high-performance liquid chromatography. J Chromatogr A. 2001; 913:447-453.

46. Titier K, Lagrange F, Péhourcq F, Edno-Mcheik L, Moore N, Molimard M. High-performance liquid chromatographic method for the simultaneous determination of the six HIV-protease inhibitors and two non-nucleoside reverse transcriptase inhibitors in human plasma. Ther Drug Monit. 2002; 24:417-424.

47. Turner ML, Reed-Walker K, King JR, Acosta EP. Simultaneous determination of nine antiretroviral compounds in human plasma using liquid chromatography. J Chromatogr B Analyt Technol Biomed Life Sci. 2003; 784:331-341.

48. Usami Y, Oki T, Nakai M, Sagisaka M, Kaneda T. A simple HPLC method for simultaneous determination of lopinavir, ritonavir and efavirenz. Chem Pharm Bull. 2003; 51:715-718.

49. Weller DR, Brundage RC, Balfour HH Jr, Vezina HE. An isocratic liquid chromatography method for determining HIV non-nucleoside reverse transcriptase inhibitor and protease inhibitor concentrations in human plasma. J Chromatogr B Analyt Technol Biomed Life Sci. 2007; 848:369-373.

50. Hirabayashi Y, Tsuchiya K, Kimura S, Oka S. Simultaneous determination of six HIV protease inhibitors (amprenavir, indinavir, lopinavir, nelfinavir, ritonavir and saquinavir), the active metabolite of nelfinavir (M8) and non-nucleoside reverse transcriptase inhibitor (efavirenz) in human plasma by high-performance liquid chromatography. Biomed Chromatogr. 2006; 20:28-36.

51. Donnerer J, Kronawetter M, Kapper A, Haas I, Kessler HH. Therapeutic drug monitoring of the HIV/AIDS drugs abacavir, zidovudine, efavirenz, nevirapine, indinavir, lopinavir, and nelfinavir. Pharmacology. 2003; 69:197204.

52. To KW, Liu ST, Cheung SW, Chan DPC, Chan RCY, Lee SS. Pharmacokinetics of plasma efavirenz and CYP2B6 polymorphism in southern Chinese. Ther Drug Monit. 2009; 31:527-530.

53. Rodriguez-Novoa S, Barreiro P, Rendón A, JiménezNacher I, González-Lahoz J, Soriano V. Influence of $516 \mathrm{G}>\mathrm{T}$ polymorphisms at the gene encoding the CYP450-2B6 isoenzyme on efavirenz plasma concentrations in HIV-infected subjects. Clin Infect Dis. 2005; 40:1358-1361.

54. Xu BY, Guo LP, Lee SS, Dong QM, Tan Y, Yao H, Li LH, Lin CK, Kung HF, He ML. Genetic variability of CYP2B6 polymorphisms in four southern Chinese populations. World J Gastroenterol. 2007; 13:2100-2103.

55. Guan S, Huang M, Li X, Chen X, Chan E, Zhou SF. Intraand inter-ethnic differences in the allele frequencies of cytochrome P450 2B6 gene in Chinese. Pharm Res. 2006; 23:1983-1990.

56. Guan S, Huang M, Chan E, Chen X, Duan W, Zhou SF. Genetic polymorphisms of cytochrome P4502B6 gene in Han Chinese. Eur J Pharm Sci. 2006; 29:14-21.

(Received January 9, 2014; Revised July 29, 2014; Accepted August 1, 2014) 